\title{
Mediated Reading of Children's Literature as Paradigmatic Scenario to Develop Emotional Competence ${ }^{1}$
}

\author{
Enrique Riquelme ${ }^{2}$ \\ Universidad Católica de Temuco \\ Felipe Munita \\ Universidad Católica de Temuco \\ Universidad Autónoma de Barcelona
}

\begin{abstract}
In the reading, we explore specific scenarios that set the context for the emotional experience, named paradigmatic scenarios. In this essay, the authors highlight the contributions of children's literature reading in their social and emotional development through a process called mediated reading. In this process, the adult reader operates as a mediator of emotional experience of "fictional" characters in the narrative, the story and those real processes that characterize children's context and life experience. This theoretical study ends by discussing the scope of children's literature reading process mediation as a tool that contributes school inclusion, and allows interaction between cognitive and affective aspects in formal education.
\end{abstract}

Keywords: children's literature, mediated reading, emotional competence, paradigmatic scenarios

\section{Leitura Mediada de Literatura Infantil como Cenário Paradigmático no Desenvolvimento de Competência Emocional}

\begin{abstract}
RESUMO - Na leitura, exploram-se cenários específicos que estabelecem o contexto para a experiência emocional, os quais são chamados cenários paradigmádicos. Neste trabalho, os autores destacam as contribuições da leitura de literatura infantil para o desenvolvimento socioemocional da criança, por meio do processo denominado leitura mediada. Nesse processo, o leitor adulto media a experiência emocional de personagens fictícios da narrativa, a história e os processos reais que caracterizam o contexto e a experiência de vida da criança. Conclui-se este estudo teórico com a discussão do alcance do processo de mediação na leitura de literatura infantil como uma ferramenta que contribui para a inclusão escolar e permite a interação de aspectos cognitivos e afetivos na educação formal.
\end{abstract}

Palavras-chave: leitura infantil, leitura mediada, competência emocional, cenários paradigmáticos

The foundations of emotional development are built from the early stages of development (Fonagy \& Target, 1999). At these stages, the interaction with primary caregivers and other principal agents of socialization (such as formal and informal educators) are a basic reference for the child in relation to the ways of approaching the world and being an active agent on it.

We approached emotions from a functional and social point of view. To Campos, Mumme, Kermoian and Campos (1994), "emotions are conceptualized as flexible, contextually bound, and goal directed" (p. 284). Briefly, this framework emphasizes the communicational process in the negotiations between the social context and our objectives (Witherington \& Crichton, 2007). Emotion is one of the first ways to learn (Guidano, 1991), each human interaction implies an opportunity to teach and learn about emotions, especially primary affective experiences with caregivers, which give us a starting point on emotional life and emotional abilities. For example, recognition and understanding of emotions, emotional regulation, or "emotional competences" that we can "see" in regular interactions (e.g. social referencing, early forms of empathy, anticipation of feelings, communication

1 Support: This article was developed within the framework of the project FONDECYT 11140311

2 Address for correspondence: Andrés Bello 724, depto 1606, IX Región, Temuco, Chile. E-mail: eriquelme@uct.cl with others, prosocial behaviors) and games (e.g. "peek-aboo").

The underlying hypothesis is that children's experiences of emotional well-being, particularly within their family environment facilitate the process that leads to their understanding of emotions (Pons, Rosnay, Doudin, Harris, \& Cuisiner, 2006).

School and preschool scenarios give children a new platform to explore and learn about the world; friends, peers, and teachers arise as new references to compare and share their experiences with, as well as new possibilities for the child to develop or restrain his or her emotional competences and abilities.

At the same time, the possibility to work with symbols and imagination amplifies these possibilities, and the power of imagination opens new windows of interaction. In "any world" of interaction, not only in the real world but also in the fictional one, children need a reference to mediate and guide this exploration; especially in the field of emotion. One needs a reference to talk about emotions and the situations that activate them. The underlying hypothesis here is that children's symbolic experience allows them to explore and understand the emotional world and, "in the real world", the development of emotional competence.

In any of these scenarios, culture, language, and communication have a key role in emotional development, 
and in the development of emotional competences (Saarni, 1999; Riquelme \& Montero, 2013; Riquelme, Munita, Jara, \& Montero, 2013).

The potential of a joint exploration through language and enhancement of emotional development is presented daily in real and fictional scenarios; these contexts of interaction can be an adequate working space for enabling and simultaneously exploring the appropriate emotional responses depending on the needs, context, intentions, etc. Those situations give us an "emotional script" according to the situation and social context.

The possibilities to talk about emotions using a particular emotional vocabulary in a particular context are also facilitated by the children's capabilities and mediation of the cultural context in which this "paradigmatic scenario" takes place (De Sousa, 1987).

Our hypothesis is the following: We are made familiar with the vocabulary of emotion by association with paradigm scenarios. These are drawn first from our daily life as small children and later reinforced by the stories, art, and culture to which we are exposed. Later still, in literate cultures, they are supplemented and refined by literature. Paradigm scenarios involve two aspects: first, a situation type providing the characteristic objects of the specific emotion-type (where objects can be of the various sorts identified in chapter 5), and second, a set of characteristic or "normal" responses to the situation, where normality is first a biological matter and then very quickly becomes a cultural one. (De Sousa, 1987, p. 182)

A paradigm scenario is, therefore, understood as a prototypical situation that reflects what is culturally expected in several areas; particularly in the emotional level. Thus, this scenario provides us guidance in the complex world of emotions, for example, the correct interpretation of what happens to us (culturally speaking), in the exploration of the language of our emotions and feelings, as well as exploring the emotional scene which allows us to follow a predictable script of "emotional" action. These paradigm scenarios integrate paradigmatic scripts that enable us to understand how we learn the vocabulary of emotions and therefore how we learn to identify and classify them.

The basic emotions which we are biologically endowed in an evolutionary process (Damasio \& Damasio, 2007; Ekman, 2007; Ledoux, 2003) give us a base of commonality and universality, but it is culture that allows us to put into words what we are feeling, why we feel a certain way, the appropriateness of a given emotion, and the internal and external evaluation of this emotion (Pocock, 2010). Consequently, we can "observe" the construction of the cultural significance of emotions in an individual story, through the analysis of characteristic scripts of different paradigm scenarios.

In these scripts and scenarios, we can observe and be part of the development of the cultural significance of emotions and different emotional abilities in children, such as the expression of emotions in a proper way, understanding one's own and others' emotions, and regulating them; those skills are usually named emotional competences (Denham, 1998, 2007; Saarni, 1999).

In this article, we reflect on a proposal for the development of emotional competences based on the mediated reading of children's literature as a context of regulated interaction or mediated experiences. In this proposition, mediated reading of children's literature could be considered a fictional paradigmatic scenario, to explore emotion through dialogue and reflection with children about the different dimensions of the emotions in the text, such as causes, consequences, intentions, facial expression, and empathy, to promote the development of emotional competences.

\section{Paradigmatic Scenarios and Emotional Competence}

We have tried to emphasize the educational role of paradigmatic scenarios, highlighting the role of social mediators in modeling emotional states and their regulation. In this process we develop our emotional competences; this approach implies that emotional competence can be acquired and developed and does not constitute an unchangeable aspect of the individual (Riquelme \& Montero, 2013; Saarni, 1999).

Although components of emotional competence can vary according to theoretical emphasis as well as the developmental periods or contexts observed (Saarni, 1999), in this study we will highlight the following four basics competences: emotion recognition, expression of emotion, emotion regulation and empathy.

Emotion recognition is defined by Saarni (1999) as "the ability to discern and understand the emotions of others, using situational and expressive keys that have some degree of social consensus, as well as emotional significance" ( $p$. 106). In this ability, facial emotion recognition constitutes - along with voice and posture - a main cue, usually called terminal display of emotion.

At pre-school age, children can infer basic emotions from facial expressions and understand the consequences of these emotions, just as they are able to differentiate their own emotions from other people's emotions (Denham, 2007). During school years, social interactions with peers allow children to recognize a broader range of emotions and to realize that the expression of an emotion is not necessarily in line with the experience of that emotion itself, in a process that implies recognition of the difference between an "internal" and an "external" world (Harris, Donnelly, Guz, \& Pitt-Watson, 1986).

The expression of emotion refers to the ability to send affective messages in accordance with the social context and the person's goals. In this way, the expression of an emotion is important information for oneself and for others, and can serve as a condition precedent of the experience and expression of others' emotions (Denham, 2007).

During school age, the expression and experience of emotion become more complex. Children learn that their goals are not only met by expressing their emotions in a more intense and direct way. This ability should imply having in mind a representation of how our emotional expression affects others and to take this into account in one's selfrepresentation strategies. Within this process, socialization plays a crucial role, transmitting the rules and cues about when and where it is possible to express a particular emotion, and especially to whom to do so (paradigmatic scenario). 
Recognition and expression of emotions require regulation, especially when the presence/absence of emotional experience and/or its expression can interfere with an individual's own goals and the particular scripts of the social context or paradigmatic scenario. During infancy, emotional regulation is strongly supported by adults, but in the preschool age autonomous strategies such as distraction or separation are developed (Riquelme \& Montero, 2013).

School age children can redefine these strategies and display different ones for specific contexts and persons. For example, they can use their imagination and fantasy, and cognitive problem-solving strategies (Denham, 2007). Emotional regulation then integrates the behavioral expression that is implied within the social relations dynamics.

In this way, those emotional competences fit with the social rules admitted under some specific social context (Saarni, 1999). These conditions are usually explicit in patterns of interactions (scripts) in a particular scenario, but ultimately these rules are implicit and those scripts are internal.

Scripts of a paradigmatic scenario are set in motion by caregivers, and maintained in behavioral regularities that make them easily recognizable by the child. In this regard, parents, as cultural mediators, lead to practicing paradigmatic scripts and emotional tools to "play" these scripts (Rodríguez, 1998).

Emotional competence is then reinforced in a particular scenario, and the internalization of this script is fundamental for a proper adjustment to social parameters from which, emotionally speaking, we "learn to be". We can be more or less competent in a particular context, but our survival may depend on this emotional competence.

However, our emotional competence in a particular scenario does not guarantee a success in other paradigm scenarios. A regular context - for example, domestic violence - can constitute a paradigmatic scenario with a particular emotional script, and a child can learn how to be competent in the expression and recognition of emotions in this scenario, but this does not guarantee that these skills acquired in one context are those expected in a safe context.

Therefore, emotional competences that have been developed and operated in a stable paradigmatic stage (have been functional) might be used in another, even though this new scenario is based on different scripts, in which those competences are no longer functional.

The emotional "incompetence" evidenced in a new setting could then consist in the confusion of scripts, when kids fail in the attempt to detect the similarity of the current situation and the original model in which they "build" the emotion (Rodríguez, 1998). In this framework, "The irrationality of a genuine emotion perception involves a perception of a situation in terms of a script that does not resemble objectively" (De Sousa, 1987, p. 146).

So we can ask ourselves about the possibility of expanding or developing competences when, as we have seen, these tend to be self-maintained for their functionality and particularly because in childhood the world that our caregivers show us is the only reality and in this world we must develop our emotional competences.
In this way, competences can be developed in contact with different scenarios. New paradigmatic scenarios can be explored, new paradigmatic scripts can be discovered and new competences may emerge or develop in a context of safe exploration. Children's literature gives us a stable scenario and the mediation of this reading allows us a safe way of exploration.

\section{Exploring "Fictional" Paradigmatic Scenarios Through Children's Literature, an Alternative to Emotional Script Exploration and Development of Emotional Competences}

According to Rodríguez (1998), the paradigmatic scripts will settle down on us, first in our daily lives as children. Later we find abundant reinforcement in countless stories which we are exposed to as listeners, then later extended and refined by literature.

A paradigmatic scenario can be constructed in fictional terms, and literature can become a world where it is possible to explore paradigmatic scripts in a safe and stable way. This is the fundamental idea that we propose: reading children's literature can operate as a paradigmatic fictional scenario. But how is this possible?

From an early age, children are able to identify and differentiate worlds of fantasy and reality in the field of literature (Harris, 2000, 2012; Nikolajeva, 2012; Oatley, 1999). For example, Munita and Riquelme $(2009 ; 2013)$ have proposed the architecture of fiction, they base this idea on the interaction of notions of enunciative pact, that is the text should implicitly invite the reader to accept as possible the comparisons between fiction and reality, and de-coupling mechanism which, in essence, allows the child go back and forth between the real and the fictional world without being confused. Despite its fictional characters and the fact that they do not have a direct correspondence with the "real" world, it has the ability to represent the everyday world as if it were (Harris et al., 1986).

Following this idea, in the articulation of literature and development, we can accept statements assume that fiction allows the reader to explore the emotional and mental states of the characters living in the text. They have the ability to "represent" their own emotional states of human life, acting in a universe ruled by certain laws of probability that make them "believable" to the child reader's eyes. Thus, given the likelihood principle that characterizes the good stories, the child reader can identify these emotional states in a process of empathy for characters that get to "live" situations and interact in ways similar to him or her (Coombs, Tolson, Huang, \& Lee, 2009).

In this new scenario, children can "observe" feelings, behaviors, and also observe the causes that lead the characters to act or feel in a certain way, and the consequences that are caused by such actions and/or emotions.

The literary text and particularly children's narratives operate as a platform for interaction and emotional literacy for the child reader/listener. Considering the world of fiction as a representation of the real world, the text allows us to name and recognize states of mind that we can compare with 
our own experience. "The writers help us to name the states of mind which passed through, to appease them, to know them better, to share them. Through their stories we write our own between the lines" (Petit, 1999, p. 37). In this way, we reinforce the idea of early and intensive contact with literature as a platform to attribute emotional states to others, as well as the ability to recognize and regulate them on us.

Children's literature has always given scenarios from which we explore the world; good literature also invites us to shed one's certainties and see this fictional world as an alternative to the real one being stable in the written word (enunciative pact). At the same time, our development allows us to differentiate and explore reality and fiction without confusing both worlds (decoupling mechanism). Text content implicitly brings a new paradigmatic scenario, which is even simplified to the age of the reader and a paradigmatic script that various actors play.

This fictional scenario gives us the opportunity to explore and decompose its emotional script, and by our own self-referential as humans - meaning that any perception highlights aspects of the perceiver as well as his or her object of perception (Guidano, 1991) - we are "forced" to see ourselves and engage in the story while we "hear" and "see" the emotional world of the participants. In Vygotsky's words:

The passions and fates of imaginary characters, their joys and sorrows move, disturb, and excite us; despite the fact that we know these are not real events, but rather the products of fantasy.

This occurs only because the emotions that take hold of us from the artistic images on the pages of books or from the stage are completely real and we experience them truly, seriously, and deeply. (2004, p. 20)

However, the exploration of the paradigmatic scenario and its emotional scripts from the fictional world require a guide that enables the mediation between our internalized emotional scenarios and scripts. In this way, this process requires an adult reader to facilitate and accompany the child in the exploration of this new scenario. These processes have been called mediated reading (Munita \& Riquelme, 2009; Riquelme \& Montero, 2013; Riquelme \& Munita, 2011).

\section{Mediated Reading of Children's Literature: The Exploration of Paradigmatic Scripts Through Language and Fantasy}

When we read literature, we accept the enunciative pact that the author and his work states. In many cases, these fictional constructs illuminate certain aspects of our everyday lives, giving us a new sense that we have not seen before the encounter with the work. The same occurs in children's readers (or listeners), who come into contact with the literary language, especially the language of the story.

Consequently, we accept "imaginary vehicles" delivery by literature - even when such statements assume fiction (Munita \& Riquelme, 2009) - allowing the reader to explore the emotions and mental states of the characters who live in the text. In this context, conceiving the literature as an "imaginary vehicle" means to assume, as Petit (1999) suggests, that despite its fictional characteristic (hence the term "imaginary"), the text is able to "mobilize" in the reader (hence the idea of "vehicle") a range of information about himself, about his relationship with others and the world around him - e.g. information about the emotional states and situations in which these states can be developed. Now, when we speak about the first approaches to literature, it is also necessary to refer to the mediation processes of reading. In the light of the Vygotskian concept of mediation, the mediator can broaden reading, providing the child the first approaches to the book, creating instances of shared reading in a process in which emotions and time create a welcoming and rewarding reading. There, the mediator demonstrates his own joy of reading to transmit this desire on the other person. In this process, the mediator facilitates a reading tour of words that make up the world of fiction and its paradigmatic scenario. This process keeps the connection between the meaning of those words and the real world in which the reading is developed.

In the exploration of paradigmatic scenarios and emotional scripts through reading we build a relationship between three components, such as: (a) connecting the narrator to the story, (b) the narrator with the audience and (c) the audience with the story. This process is accomplished largely by the mediator's ability to transmit feelings and emotional atmospheres typical of the narrative, allowing the exploration of these worlds narrated to the child. This process is called mediated reading.

In the mediated reading processes different communication routes converge and these are channeled through the mediation of an adult. The mediator fosters the child's emotional approach to the book, and by extension is introduced in various emotional states inhabited by the characters throughout the story in the frame of a paradigmatic scenario. Literary language, visual storytelling, pauses, reading pace and rhythm, facial expression and movements of the mediator, are all components of a scaffolding process that helps children to delve into their emotional paradigms of the text.

This implies a previous work of the mediator with the book detecting and marking nuances. Therefore nuances are given or implied by the general tone of the text. So, we must consider two main areas: the literary corpus (what to read?) and the diversity of languages used by the reader/mediator (how to read?)

\section{The Literary Corpus}

For mediated reading purposes a particular genre as corpus-based could be used: the picture book. That is, books which use images as narrative language, full of meaning and able to narrate in parallel with the story. This allows the child to observe during the reading session a series of illustrations carrying meaning in the context where the story is told. Often the illustrations transmit the emotional atmospheres of the text to the reader, either on the face of the characters, in the expressive use of certain colors and shades, or through visual emphasis. We believe that joining this graphic account with the readers' oral narratives opens a window for the child to the immersion in characters' lives, and the emotional scripts and paradigmatic scenarios. 


\section{The Language Used by the Reader / Mediator}

In this joint exploration of literary and emotional universe of books, the stories that are read are as important as the manner in which they are told. In reading sessions the mediator acts as a "resonance box" of the narrated world; he or she echoes the emotional atmosphere of the story.

To do this, the narrator must supplement the reading of the text with other constituents of nonverbal and para-verbal language. In the latter, intonation, tone and adequate pace will be determinants to channel a plausible and attractive script of the story. For the nonverbal aspects, kinesics is a great way to regulate the actions of the narrative and emotional states that this conveys. The tension or calm in a given passage, the joy or sadness of the characters, the surprise for unexpected plot twists - everything can be conveyed in facial expressions and body movements of the reader.

All the components previously described imply the reading and transmission of an emotional world. The mediator must be able to recognize and transmit emotional scripts and paradigmatic scenarios from the fictional world, particularly, those key emotional aspects of the story.

A final and central component of the mediated reading is an open conversation with children. In this context there will be a revision of the most significant emotional aspects of the story, through a collective dialogue about the book, in which children can express their emotions and feelings about what they have read or heard.

Simple questions facilitate this dialogue and promote the exploration of emotions, in both worlds of fiction and reality. For example, a dialogue after the reading could include some of these open questions, such as: How was the face of this character? Why did she or he make that face? Would you make that face? Show me that face! What is the name of that emotion? Why is this character so sad? Do you think is it right to feel this? Could he/she have done something different to feel in a different way? Is it right the way in which he/she expresses his/her emotions? Why? Do you know someone who feels like this character? How we can help him/her?

These questions (not necessarily all of them) are just a guidance to enhance emotional skills development, such as the recognition and regulation of emotion or empathy. The dialogue that arises allows a journey from the world of fiction and its characters, to the world of reality and the people who compose children's environment. Thus, the two-way journey from reality to fiction is over. Saarni (1999) highlights the central role of such dialogue and language:

The ability to represent our emotional experience through words, imagery, and symbolism of varied sorts promotes two major accomplishments: a) behaviorally, we can communicate our emotional experiences to others across time and space and b) conceptually, by having access to representations of our emotional experiences, we can further elaborate on them, integrate them across context, and compare them with others' representations of emotional experiences. (p. 131)

The objective is to enhance the possibilities for children to interact with an adult through language - in this case, language about emotions. Expanding the emotional scripts and emotional competences require we offer to children the opportunities to interact in a new and safe scenario, in this case through language and history. New readers need mediators who can make texts easier to explore, especially regarding the emotional contents of the story.

This mediating process facilitates emotion recognition, in both fictional worlds and characters, and in the readers' real world. In this process, higher psychological functions are formed through the mediator's external regulation (interpersonal regulation), which can help to guide a child's internal regulation (intrapersonal regulation). By doing this, the adult leads the mediated reading activity and the surrounding conversations. The mediating adult should have the ability to ask appropriate questions, discuss and contextualize fiction and reality, and represent feelings and the story's emotional atmosphere (Riquelme \& Montero, 2013; Riquelme et al., 2013).

\section{Conclusion}

Educational experiences have slowly begun to include emotional aspects, in this context, emotional literacy is a fundamental process for the development of empathy and emotional skills as well as pro-social behavior in children, or "emotional competences" (Jennings \& Greenberg, 2009). Several authors (Colwell \& Hart, 2006; Coppock, 2007; Figueroa, 2008; Richardson \& Cols, 2009) have raised numerous ways to promote emotional literacy and social development of children, such as the structuring of environments in the classroom, including family and community; working with rhythm games and songs, focus groups, and circle time, among others. Regretfully, emotional education is still a secondary objective in the academic context.

Socio-emotional education and academic priorities should not be two independent learning processes for children. Rather, these considerations lead us to think of them as one integrated way to enhance adequate social and individual development. In an effective mediated reading the child favors the naturalness of the exploration of mental contents, as well as builds the contextualized meanings of the interaction.

In the mediated reading of children's literature, stories are explored through a series of charged emotional interactions. In this exploration the adult reader operates in the zone of proximal development of the child reader, building him linguistic scaffolding, which facilitate the recognition of emotions in both world the fictional and the real.

A basic dialogue makes the difference between doing the same (follow the internalized emotional script), and trying to open new emotional responses and competences (challenge the old emotional scripts in a new and secure scenario). In the text and language, a new paradigmatic scenario emerges and we are able to explore its scripts, learning vicariously from the characters of this fictional world, in a secure way. Emotional competences, such as the recognition of facial emotions are then amplified and tested in this new world.

As mentioned, the Vygotskian model is fundamental to the processes of mediated reading. In this journey, exploration of emotions and emotional literacy (such as emotion recognition) are mediated during the reading process and 
emotional processes are placed in context, facilitating the child's understanding of the emotional states of a particular character and interaction in general. Thus, the narrative gathers a scanning platform. In this basic process, people are reading and commenting on a literary text. Integrating the key elements to explore the mental states of others provides readers to share these mental states in a non-forced, inclusive and safe environment (Ainscow, 2005).

\section{References}

Ainscow, M. (2005). Using evidence to encourage inclusive school development: Possibilities and challenges. Australasian Journal of Special Education, 29(2), 12-21.

Campos, J., Mumme, D., Kermoian, R., \& Campos, R. (1994). A funcionalist persective on the nature of emotion. Monographs of the Society for Research in Child Development. The Development of Emotion Regulation Biological and Behavioral Considerations, 59(2-3) 284-303.

Colwell, M., \& Hart, S. (2006). Emotion framing: Does it relate to children's emotion knowledge and social behavior? Early Child Development and Care, 176(6), 591-603

Coombs, R., Tolson, H., Huang, T-Y, \& Lee, Y. (2009). Character education: Lessons for teaching social and emotional competence. Children \& Schools, 31(2), 71-78.

Coppock, V. (2007). It's good to talk! A multidimensional qualitative study of the effectiveness of emotional literacy work in schools. Children \& Society. 21, 405-419

Damasio, H., \& Damasio, A. (2007). Social conduct, neurobiology, and education. In M. Suárez-Orozco (Ed.), Learning in the global era: International perspectives on globalization and education (pp. 104-117). London: The University of California Press and the Ross Institute.

De Sousa, R. (1987). The Rationality of emotion. Cambridge: The MIT Press

Denham, S. (1998). Emotional development in young children. New York: Guilford

Denham, S. (2007). Dealing with feelings: How children negotiate the worlds of emotions and social relationships. Cogniţie, Creier, Comportament / Cognition, Brain, Behavior. 11(1), $1-48$.

Ekman, P. (2007). Emotions revealed (2d. Ed.). New York: Holt Paperbacks.

Figueroa, M. (2008). Building emotional literacy: Groundwork to early learning. Childhood Education, 84(5), 301-304.

Fonagy, P., \& Target, M. (1999). An interpersonal view of the infant. In A. Hurry (Ed.), Psychoanalysis and developmental therapy (pp. 3-31). Madison: International University Press.

Guidano, V. F. (1991). The self in process. New York, NY: Guilford.

Harris, P. (2000). The work of imagination. Hoboken: Blackwell Publishers Ltd.

Harris, P. (2012). Trusting what you're told: How children learn from others. Cambridge: Harvard.

Harris, P., Donnelly, K., Guz, G., \& Pitt-Watson, R. (1986). Children's understanding of the distinction between real and apparent emotion. Child Development, 57, 895-909.
Jennings, P., \& Greenberg, M. (2009). The prosocial classroom: Teacher social and emotional competence in relation to student and classroom outcomes. Review of Educational Research. $79(1), 491-525$.

Ledoux, J. (2003). The emotional brain, fear, and the amygdala. Cellular and Molecular Neurobiology, 23(4/5).727-738.

Munita, F., \& Riquelme, E. (2009). La arquitectura de la ficción y el lector infantil: Conjeturas sobre el proceso de articulación en la comprensión literaria. Estudios Pedagógicos, 35(2), 261-268.

Munita, F., \& Riquelme, E. (2013) Leer con otros para leerse a sí mismo. La lectura mediada de literatura infantil y sus aportes en el desarrollo de las competencias emocionales del niño. In Bibliotecas Escolares CRA, Unidad de Currículum y Evaluación (Eds.), A viva voz: Lectura en voz alta (pp. 30-45). Chile: Ministerio de Educación de Chile.

Nikolajeva, M. (2012). Reading other people's minds through word and image. Children's Literature in Education, 43, 1-19.

Oatley, K. (1999). Why fiction may be twice as true as fact: Fiction as cognitive and emotional simulation. Review of General Psychology, 3(2), 101-117.

Petit, M. (1999). Nuevos acercamientos a los jóvenes y la lectura. México DF: Fondo de Cultura Económica.

Pocock, D. (2010). Emotions as ecosystemic adaptations. Journal of Family Therapy, 32(4), 362-378.

Pons, F., Rosnay, M., Doudin., Harris, P., \& Cuisiner, F. (2006). Emotion understanding as a reflective emotional competence: Between experiences and symbols. In F. Pons., D. MarieFrance., L. Lafortune., P. Doudin., \& O. Albanese. (Eds), Toward emotional competences (pp. 19-32). Denmark: Aalborg University Press

Riquelme, E., \& Montero, I. (2013). Improving emotional competence through mediated reading: Short term effects of a children's literature program. Mind, Culture, and Activity, 20(3), 226-239.

Riquelme, E., \& Munita, F. (2011). Literatura infantil y alfabetización emocional. Estudios Pedagógicos, 37(1), 269-277.

Riquelme, E., Munita, F., Jara, E., \& Montero, I. (2013). Reconocimiento facial de emociones y desarrollo de la empatía mediante la lectura mediada de literatura infantil. Cultura $y$ Educación, 25(3), 375-388.

Rodríguez, M. (1998, Sept.). Sobre la racionalidad de las emociones. Communication at the II Congreso Internacional de la Sociedad Española de Filosofía Analítica, Universidad Complutense de Madrid.

Saarni, C. (1999). The development of emotional competence. New York: Guilford

Vygotsky, L. (2004). La imaginación y el arte en la infancia. Madrid: Akal

Witherington, D., \& Crichton, J. (2007). Frameworks for understanding emotions and their development: Functionalist and dynamic systems approaches. Emotion, 7(3), 628-637.

Recebido em 17.01.2014

Primeira decisão editorial em 06.05.2015

Versão final em 14.05.2015

Aceito em 07.07.2015 